\title{
De la emoción a la acción: El miedo y la violencia xenófoba de las re- des sociales aterrizan en Ibarra
}

\author{
From emotion to action: Fear and xenophobic violence of \\ social media land in Ibarra
}

\author{
Edison Vicente Gordillo Vargas \\ Ingeniero en Finanzas, Universidad Central del Ecuador, Estudiante de Maestría de Investigación \\ en Sociología Política de FLACSO Ecuador \\ Email: edygordillo@gmail.com
}

Doi: https://doi.org/10.22267/rceilat.214849.98

\begin{abstract}
Resumen
La madrugada del 20 de enero de 2019 en la ciudad de Ibarra - Ecuador, ciudadanos se organizaron por redes sociales para aterrorizar, agredir, y expulsar a inmigrantes venezolanos de sus hogares mediante la consigna de una "limpieza social" inmediatamente después del femicidio de Diana Carolina. El objetivo de este trabajo es analizar el comportamiento colectivo del fenómeno social ocurrido el 20 de enero de 2019. Se propone estudiar el caso desde la perspectiva sociológica de la acción colectiva de las emociones, la teoría de las redes y la figuración del Otro, abordar el hecho xenófobo y dar cuenta del mecanismo que produjo la movilización. Las emociones agresivas como la cólera o la ira permiten invisibilizar la línea divisoria en el Dilema Bueno/Malo, estas emociones comprometen a los manifestantes de tal forma que serán capaces de hacer lo que sea, para solucionar o anular el problema. Esto explica la sensación de que las redes sociales hayan legitimado el accionar de los asistentes y su acción fuera vista como algo "bueno y necesario", retratando a los agresores como héroes.
\end{abstract}

Palabras Clave: Femicidio; Redes sociales; Shock moral; Limpieza social; Acción colectiva.

\begin{abstract}
At dawn on January 20, 2019 in the city of Ibarra - Ecuador, citizens organized through social media to terrorise, attack, and throw out Venezuelan migrants from their homes through the slogan of a "social cleansing" immediately after Diana's femicide Carolina. The objective of this work is to analyze the collective behavior of the social phenomenon that occurred on January 20, 2019. It is proposed to study the case from the perspective of the sociology of the collective action of emotions, the theory of networks and the figuration of the Other, address the xenophobic act and account for the mechanism that produced the mobilization. Anger, anger, and other aggressive emotions do not always represent a compelling approach; they engage protesters in the Bad / Good dilemma. Protesters felt better avoiding this dilemma than having their options restricted because
\end{abstract}


insubordinate emotional expressions are excluded from the start. It is for this reason that social networks legitimize the actions of the attendees and their action was seen as something "good and necessary", that day the aggressors were heroes.

Keywords: Femicide; Social networks; Moral shock; Social cleansing; Collective behavior.

\section{Introducción}

Resultado de la crisis política y socioeconómica que atraviesa Venezuela, la cifra de personas que han decidido abandonar este país se ha disparado. De acuerdo con la información provista por el Alto Comisionado de las Naciones Unidas para los Refugiados (ACNUR) es posible situar el inicio del éxodo venezolano en 2015 pasando de 695.000 a fines de año a más de 4 millones a mediados de 2019. Los países latinoamericanos que acogen a la gran mayoría de venezolanos son: Colombia alrededor de 1,3 millones, seguido por Perú, con 768.000, Chile 288.000, Ecuador 263.000, Argentina 130.000 y Brasil 168.000. México y los países de América Central y el Caribe también albergan un gran número de refugiados y migrantes de Venezuela.

De acuerdo con la información proporcionada por el Instituto Nacional de Estadística y Censos (INEC), desde el 2008 a 2017 se mantenía un incremento aritmético constante en el ingreso de la población migrante en Ecuador, sin embargo, a fines de 2018, se registra el ingreso de más de dos millones de extranjeros de distintas nacionalidades, de estos, el 39,4\% son de nacionalidad venezolana. Entre los registros levantados por ACNUR la población venezolana considera a Ecuador como un lugar de tránsito, siendo los lugares de destino privilegiado Perú y Chile.

Todo este tránsito de migrantes por todo el territorio nacional ha construido de forma lenta y escalada un imaginario en el migrante venezolano como si se tratase del Otro $^{1}$, del enemigo, de un sujeto que trae consigo inseguridad, además que su mano de obra es percibida como una competencia desleal por los ecuatorianos.

El cotilleo que en épocas anteriores no pasaba de un pequeño grupo de personas, ahora, con las redes sociales los mensajes se amplifican y se vuelven virales. Como ejemplo, una vendedora ambulante de nacionalidad venezolana llamó despectivamente a los ecuatorianos:"indios feos”, razón por la cual se abrió un debate migratorio $^{2}$, el video, originalmente subido a la página de Youtube, con un toque

1 Según Levinás el Otro representa la presencia de un ser que no entra en la esfera del mismo, presencia que lo desborda, fija su "jerarquía" de infinito. Es decir, el Otro responde a aquello que no soy yo, a aquello que es anterior a mí y, gracias a lo cual yo soy quien soy.

2 La República. (2017, 16 septiembre). Venezolana tilda de «indios y feos» a ecuatorianos y desata debate migratorio | La República EC. La RepúblicaEC. https:// www.larepublica.ec/blog/2017/09/15/venezolana-tilda-de-indios-y-feos-a-ecuatorianos-y-desata-debate-migratorio/ 
cómico, y haciendo alusión de manera inicial a la situación que tienen que vivir a diario mujeres venezolanas con sus empleadores, culmina con un calificativo del ecuatoriano de indio por sus facciones. ${ }^{3}$

Esto ocasionó la rápida viralización del contenido en redes sociales, principalmente en Facebook, donde el video de la página "Aquí hablamos en serio" " tiene más de 39.000 reproducciones, y los comentarios son de todo tipo; desde la aceptación de su indigenismo, culpando a la ignorancia de la entrevistada, insultos, y atisbando los primeros brotes xenófobos en redes, por ejemplo:

- "Yo estoy en contra que vengan estas señoritas a trabajar acá...Quitan el trabajo a muchas chicas ecuatorianas. Lamentablemente hay gente ecuatoriana que da trabajo a estas personas por la mitad del sueldo básico para aumentar ingresos en sus negocios...Invito a que cada vez que veamos a un extranjero en una tienda iNo compremos nada".

- "Yo por eso ni les regreso a ver peor comprarles algo, primero nuestra gente estos se pueden meter sus helados por donde no les llega el sol". Además, estas acciones incitaron a la

3 Youtube. Venezolana llama a los Ecuatorianos indios feos y asquerosos. (2017, 14 septiembre). [Vídeo]. https://www.youtube. $\mathrm{com} /$ watch? $\mathrm{v}=\mathrm{vMlDiMUaa} 44$

4 Comentario de página de Facebook "Aquí hablamos en serio", acceso el 25 de agosto de 2019, https:// www.facebook.com/558736854146814/videos/1598611916825964/ creación contenido multimedia, como chistes y memes. ${ }^{5}$.

Se presentan tres capturas de pantalla de páginas de Facebook con carácter xenófobo. En el link ${ }^{6}$ se publican todos los memes recolectados de la página "Fuera Venezolanos Fuera”; esta página fue creada el día de la marcha para aglutinar a personas y ser punto de conexión entre los diferentes asistentes.

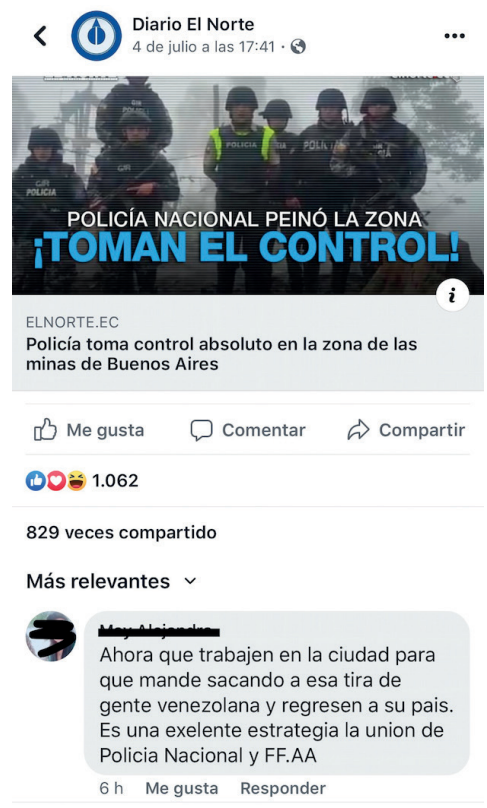

Captura 1.Post de Diario del Norte Publicadas el 4 de julio de 2018. Comentario Xenofobia 1.

5 Fuente de humor visual en internet, plataforma en la cual este tipo de lenguaje adquiere mayor relevancia cada vez, ya que el uso del lenguaje verbal se mezcla con el visual.

6 Gordillo, E. Link de Capturas de Pantalla y Transcripciones de las entrevistas. https:// n9.cl/txk6a 


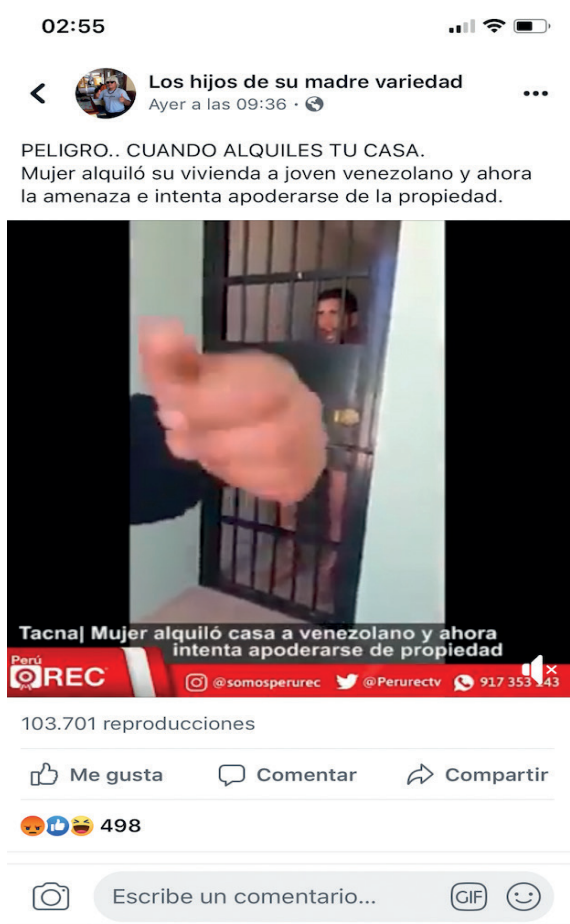

Captura 2. Post Página Facebook publicado el 11 de julio de 2018. Comentario Xenofobia 2.

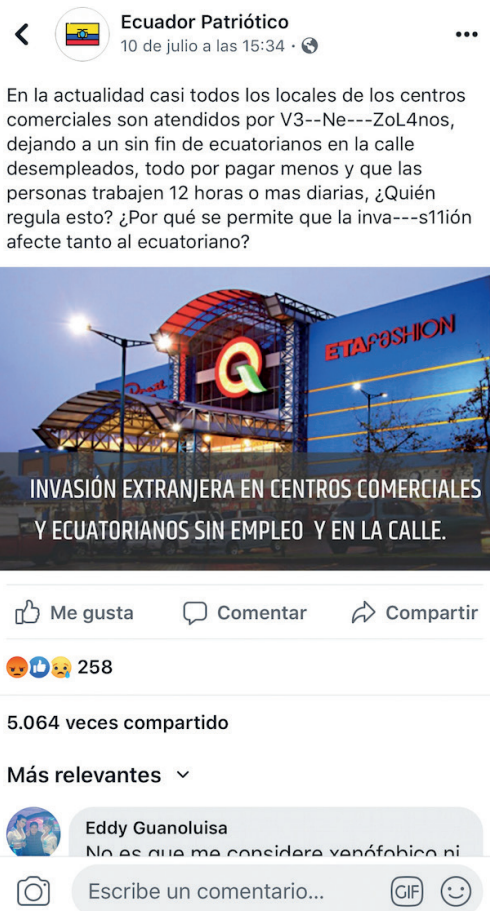

Captura 3. Post Página Facebook Ecuador Patriótico publicado el 10 de julio de 2018. Comentario Xenofobia 3.
Como podemos corroborar, antes de la marcha ya se observaban comentarios de corte xenófobo (Captura 1), incluso en medios de comunicación del norte del país, como es el Diario del Norte, donde señalan; "mande sacando a esa tira de gente venezolana y regresen a su país”, así mismo Fake News, donde se menciona que ciudadanos venezolanos intentan apoderarse de una propiedad (Captura 2) y páginas de Facebook dedicadas exclusivamente a reproducir publicaciones de tipo xenófobo (Captura 3) apelando a un nacionalismo como sugiere el nombre de la página "Ecuador Patriótico”, donde señalan "Todos los locales de los centros comerciales son atendidos por venezolanos dejando a un sin fin de ecuatorianos en la calle desempleados...".

En las capturas de pantalla anteriores, el ecuatoriano en su imaginario desea que el Estado tome cartas en el asunto frente a la migración, además, que se respete la propiedad privada de los ciudadanos y se maneje adecuadamente el gran problema del desempleo; sin embargo, las publicaciones tienen un sentido xenófobo; tomando a una minoría como chivo expiatorio de los problemas sociales.

La noche del 19 de enero, un hombre, cuchillo en mano, mantuvo cautiva a una mujer en plena calle. A pesar de haber alertado a la Policía que lo rodeaba, que mataría a su víctima si no lo dejaba ir, los policías decidieron avanzar hacia él, armados, con el fin de arrinconarlo, sin embargo, fueron testigos de cómo el hombre lanzó dos 
cuchilladas mortales sobre ella (Diana Carolina). Solo entonces, Yordi Rafael, el agresor, fue detenido ${ }^{7}$. Tras la captura, un grupo de ciudadanos acorraló al hombre y lo tiró entre golpes al piso. Los agentes tuvieron que detonar bombas lacrimógenas para disipar al grupo. Todo lo ocurrido fue grabado vía streaming en Facebook y fue compartido tantas veces que se convirtío en contenido viral.

Meses más tarde, el agresor confesaba haber robado el cuchillo de un restaurante de asados tras una discusión con Diana, allí el dueño del local de asados lo amenazó con meterlo preso por no tener los documentos en regla y fue él quien llamó a la Policía. Por esta razón tomó como rehén a Diana Carolina. "Solo pedía un taxi para irme al Perú", afirmó el agresor ante la Fiscalía. También señaló que en dos ocasiones guardó el cuchillo, en una para que Diana Carolina tomara agua y en otra para que se fuera. Pero, cuando la soltó -dijo- Diana le abrazó y señaló que se quedaría con él. Al final del relato, Yordi L. afirmó que la apuñaló porque se sintió "acorralado"s.

Después del femicidio la madrugada del 20 de enero de 2019, a modo de inquisición, ciudadanos ecuatorianos se movilizaron en masa por las calles de la ciudad de Ibarra para desalojar

7 El Comercio. (2019, 20 enero). Un hombre asesinó a una mujer tras tenerla retenida por 90 minutos en la calle en Ibarra. https://www. elcomercio.com/actualidad/hombre-asesinato-mujer-calles-ibarra.html

8 El Telégrafo. (2019, 25 febrero). Asamblea apunta a error de mando en femicidio de Diana. https://www.eltelegrafo.com.ec/noticias/judicial/12/asamblea-femicidio-casodiana-ibarra a migrantes venezolanos de los parques centrales, estos últimos fueron golpeados, lastimados y en ciertos sectores quemaron sus pertenencias ${ }^{9}$, su actuar señalaban que se justificativa como producto del feminicidio de Diana, su consigna "limpieza social" (El Universo, 21 enero 2019 b).

Al siguiente día se organiza una marcha en 11 ciudades distintas del Ecuador. Protestan por la violencia contra mujeres, en contra de la xenofobia y en contra del machismo (El Universo, 2019 c).

El fenómeno de movilización genera muchos interrogantes: ipor qué se da el pogromo la madrugada del 20 de enero en Ibarra? ¿Cuál fue el mecanismo de participación y convocatoria para el pogromo? ¿Los asistentes al pogromo eran personas de rasgos e ideas xenófobas y buscaban algún tipo de respuesta por parte del Estado? ¿Qué implicó emocionalmente para los asistentes online y offline observar la muerte de Diana Carolina? ¿Un acto violento grabado en vivo y colado en redes sociales puede ser generador de movilizaciones? ¿Podemos decir que el shock moral (término creado por James Jasper) proveniente del femicidio produjo una acción colectiva xenófoba perpetuada y apoyada por las redes sociales?

9 Turba enardecida desaloja a venezolanos en Ibarra. (2019, 21 enero a). Videos | El Universo. https://www.eluniverso.com/2019/01/21/ video/7150712/turba-enardecida-desaloja-venezolanos-ibarra/ 


\section{Método}

La metodología utilizada para la elaboración de este artículo se constituye bajo una perspectiva mixta, mediante el aparataje teórico analítico se busca explicar los motivos de la movilización y desde las entrevistas, técnica enteramente de corte cualitativo, comprobar si el análisis teórico efectuado es el adecuado.

Hay que recalcar que las entrevistas realizadas se hicieron a dos personas de niveles socioeconómicos diferentes. Andrés Játiva es un abogado con educación de cuarto nivel; el otro, Jhony, es un taxista que no tiene un nivel superior de educación, sin embargo, ambos tienen puntos diferentes de observar el fenómeno y ambos asistieron a la marcha. Andrés, cuenta con redes limitadas en cuanto a personas; el segundo cuenta con redes más amplias debido a su profesión, Jhony tiene lazos de confianza y afinidad mas profundos que Andrés en la ciudad de Ibarra por la naturaleza de movilidad de su trabajo.

\section{Análisis teórico analítico}

El suceso de la madrugada del $20 \mathrm{E}$, es el primer escenario en la historia ecuatoriana de una respuesta xenófoba masiva por parte de los ciudadanos, aún no existen estudios del mismo. Se pueden distinguir tres procesos que van de la mano y convergen en el suceso, el primero; el más importante por su transversalidad, siendo un motor aparentemente oculto que acciona todo: la figuración del
Otro; el segundo; la articulación con tecnologías actuales (teoría de redes) y por último y como resultado de las dos anteriores la movilización xenófoba o pogromo (acción colectiva). El siguiente diagrama resume las teorías utilizadas así como los sucesos.

\section{Figuración del Otro}

Para entender al Otro es necesario conocer qué es el alter y ego. Para esto necesitamos adentrarnos en la filosofía de la alteridad, esta permite que observemos a la diferencia en toda su complejidad.

"Alter es un pronombre latino formado a partir del sustantivo alius -otro, distinto, diferente-, al que se añade el sufijo -ter, que diferencia a un elemento de otro dentro de un par. Así, alter se contrapone a ego, lo otro a lo mismo, pero ambas categorías se definen de modo relacional, remiten la una a la otra hasta el punto de que la identidad individual no se concibe sin incluir en esa definición la dimensión de alteridad, otredad o diferencia, con la que cada individualidad se relaciona" (Guerrero, 2015, p. 423).

La identidad no puede basarse en argumentos solipsistas, sino que para entenderla es necesario tomar la exterioridad y los variados modos de relación con ella.

Levinas destaca cinco niveles o aspectos de la alteridad, estos son los planos: metafísico, religioso, individual, intersubjetivo y ético. Para la realización de esta investigación tomaremos los plano intersubjetivo y ético. La intersubjetividad porque "a 
través del lenguaje nos abrimos a la alteridad, la palabra siempre es una interpelación que el otro me lanza y a la que yo respondo o, al menos, tengo el imperativo ético de responder" (Guerrero 2015, p. 425), esta dimensión sería perfecta estudiarla desde las redes sociales, donde la comunicación escrita y el lenguaje son parte vital del mecanismo de preguntas y respuestas de cada publicación. El segundo plano a tomar es el de la ética, si bien Levinas señala que:

"Capto al otro como alteridad que no poseo ni puedo poseer, y esto me induce a respetar al otro en su diferencia y especificidad. La ética aflora, pues, de la confrontación directa con el rostro del otro y la actitud receptiva frente a la interpelación directa que ese rostro me lanza" (Guerrero, 2015, p. 425).

En el plano ético confluyen todos los demás planos, no nos interesa objetivar a sujetos individuales, nos interesa objetivar al colectivo xenófobo, que con la expresión pública de "limpieza social" toma acciones aparentemente éticas a nivel colectivo, cansados de la inseguridad y de un enemigo común: el migrante venezolano. A ojos de sus semejantes son observados como héroes.

“...o sea la gente aplaudía, íbamos a la calle y la gente salía a la terraza a aplaudir. En la página de "Fuera Venezolanos Fuera" decía salir con ollas y tapas para apoyar a la gente que está realizando esta iniciativa. Y la gente salía a los balcones y a las terrazas y decía: vaaamos, nos alentaban, nos daban agua, tabacos incluso" (Entrevista a Jhony taxista
Líder de la marcha, 2020).

La dimensión lingüística en la teoría de Lévinas tiene un papel central en los modos de relación con la alteridad, llega a considerar que el lenguaje es el que permite estas relaciones. La comunicación es clave dentro de esta definición. "el discurso es [...] el vínculo que no puede quedar recluido plenamente en el enunciado, porque reivindica ya desde siempre al Otro-distinto, porque habla al Otro-distinto" (Samoná, 2005, p. 432).

El lenguaje es un proceso de dar y recibir, tanto el interlocutor como el receptor intercambian información, la presencia real del otro se perpetúa cuando éste nos escucha, el lenguaje implica una conexión de lo heterogéneo.

"El otro me interpela directamente, me interroga, y al hacerlo me insta a salir de mi mismidad o ensimismamiento y responder a esa llamada que me hace a mí, situado frente a mí. Levinas habla aquí de 'solicitud', un término tomado de Heidegger que alude a la disponibilidad para atender la llamada del otro" (Guerrero, 2015, p. 433).

Las redes sociales tienen el poder de callar al Otro, las "cámaras de eco"10

10 Acorde a Ernesto Calvo es un concepto que en el área de medios y en ciencias sociales describe el modo en que ideas o información son amplificadas por una comunidad. La idea básica es que los individuos reciben una versión amplificada de la información previa de la cual ya disponen. El resultado es que la información a la cual son expuestos es una versión amplificada y "mejorada" de sus propios prejuicios. 
cumplen la función de mantener un diálogo unidireccional, es decir no existe una contraparte que señale que se está desconociendo al diferente, las redes sociales son adictivas porque se escucha un reflejo del pensamiento propio.

A modo de ejemplo en la sección de anexos, las Capturas de pantalla (4, 5, 6 y 7), muestran de manera clara cómo el contenido de Facebook se viraliza. Si una persona observa esta publicación tiene las opciones de: a) Reaccionar a la publicación con un like o emoción, o; b) Comentar su acuerdo o desacuerdo dentro de la misma. Al comentario si es de agrado de los participantes tendrás "likes" o "reacciones". La publicación trata de la creación de un grupo armado fuera del Estado que "limpiará las calles de venezolanos"; donde las reacciones de aprobación sobrepasan el millar, se observan comentarios como: "felicitaciones excelente ya era hora ponga el ejemplo hacer justicia con nuestras propias manos", "espero ver esas hermosa noticias y esas piñatas siempre paso por el puente de guajalo y del caballito por favor denos ese placer"; a lo cual la primera publicación tiene 92 me gusta, es decir 92 usuarios están de acuerdo con hacer justicia por mano propia y 59 usuarios ver colgados desde los puentes. El sentido xenófobo de las publicaciones serán observadas por usuarios que dentro de sus intereses tengan este mismo sentir.

Lévinas consideraba que la palabra oral estaba por encima de la escrita, puesto esta última estaba muerta, sin embargo, la celeridad con la que traba- ja el internet, se puede hablar del envío y recepción de información de manera instantánea, por tanto, la palabra escrita en nuestra actualidad tiene una connotación e importancia diferente. La captura de pantalla 13 fue tomada el 21 de julio de 2019, se mostraba un auto robado por aparentes delincuentes venezolanos e inmediatamente al siguiente día en la captura de pantalla 8; las personas que delinquieron de ciudadanía venezolana fueron atrapadas y ajusticiadas con mano propia. Esta celeridad en la información permite que muchas de las noticias no sean reales y sea posible crear un imaginario del Otro rápidamente.

"Solo en el discurso entre seres singulares se constituye la significación interindividual de los seres y las cosas, es decir, la universalidad" (Guerrero, 2015, p. 433). Si no existe el discurso entre pares, entonces no se puede hablar de universalidad sino, de una parte, de la parte que a mi juicio es la que se debe hablar, es la parte que está correcta. El plano del lenguaje confluye directamente con el de la ética. El bien y el mal se fundamentan en el lenguaje. Si las cámaras de eco y los filtros burbuja me muestran solo aquello en lo que la plataforma como Facebook desea mostrar entonces el Otro es anulado, por tanto, no existe esa universalidad que Lévinas menciona; esa discusión entre pares que permite la tolerancia.

\section{Teoría de Redes y Tecnopolítica}

La noche del 20E los sucesos estuvieron transfigurados por las redes 
sociales desde inicio hasta el final, absolutamente todos los eventos fueron registrados en las plataformas digitales, el contenido fue posteado y compartido miles de veces. La muerte de Diana Carolina transmitida vía streaming en Facebook, fue un detonante emocional para miles de internautas que seguían el caso de cerca. Es aquí donde se gesta un dispositivo que acciona la movilización. Una página de Facebook.

“...redes sociales tanto Facebook y los grupos de WhatsApp llevaban mucha información que fue descartada posteriormente. Pero principalmente lo que circulaba eran fotografías y videos tratando de generar o poder capturar los diálogos que se daban con esta persona que estaba en esa actitud (asesino de Diana Carolina). Luego en Facebook que hay la posibilidad de transmisión en vivo muchas, muchas personas incluyendo, muchos de las páginas de los medios de comunicación locales, empezaron a transmitir en vivo el hecho" (Entrevista a Andrés Játiva - Asistente a Marcha, 2020).

La página de Facebook que se crea es "Fuera Venezolanos Fuera" como medio aglutinador de masas que permitía compartir un número de celular en una de las publicaciones para que los asistentes a la marcha transmitan por ahí sus mensajes. Jhony, taxista asistente a la marcha, uno de los "cabecillas" de ella; menciona que la página fue fundamental para el desarrollo de la misma.

"La gente empezó a hacer lo mismo, mandar invitaciones por facebook y whatsapp. Yo ese día no trabajé así que me di el tiempo de leer todos los mensajes y ver qué pasaba...las redes sociales fueron las que comunicaron a la gente que estaba indignada; las redes sociales fueron las que pusieron el alto aquí en Ibarra (Refiriéndose a la marcha); porque las redes convocaron a la gente, la gente se fue reuniendo. Aún existe la página "Fuera Venezolanos Fuera" que fue la que convocó. Esta página fue la que tomó algo así como un acto de responsabilidad" (Entrevista a Jhony taxista Líder de la marcha, 2020).

Lo sucedido se enmarca en la teoría de la sociedad red de Manuel Castells (2001), "una sociedad cuya estructura social está construida en torno a redes de información a partir de la tecnología de información microelectrónica estructurada en Internet" (Castells 2001, 12). En esta sociedad red los procesos de acción colectiva se configuran cada vez más de forma horizontal, descentralizada y participativa (Candón Mena 2013), en donde las tecnologías juegan un papel muy importante. Las TIC's no sólo intervienen en procesos de organización y coordinación de la acción colectiva sino además en el mismo proceso de construcción del sentido de la acción. "Las redes no han servido únicamente para construir o coordinar la acción colectiva sino, sobre todo, para tejer el sentido de la propia acción y para crear un impulso constituyente en un marco de acción, pensamiento y estructuración social" (Toret, 2013, p. 19).

La comunicación vía internet permite también la difusión extensiva 
de códigos culturales y de valores a través de la transmisión instantánea de ideas en un marco que posibilita la coalición y la agregación, permite finalmente proponer estrategias de resistencia a temas globales en ámbitos o sociedades locales, sin peligro de aislamiento. Hace ya años que se percibió (Castells, 1999) que Internet permitía convertir en relevantes las experiencias cotidianas en el resto del mundo y hacer posible su articulación con muchas otras protestas que acababan aterrizando en cualquier otro lugar.

Andrés Játiva (2020) menciona que las redes sociales jugaron un papel más importante que incluso la propia marcha, porque fueron las que convocaron, las que permitieron, las que por su versatilidad hicieron posible que cientos de personas salgan a las calles en busca de "justicia".

Una de las características de los nuevos formatos de acción y movilización política ha ido consolidándose a lo largo de estos últimos diez años, es el de la capacidad de "generar discurso". Es decir, de la capacidad de construir "concepciones" compartidas. No basta solo con que se den las condiciones objetivas para que se produzca un proceso de movilización. Por ejemplo, el nombre de la página "Fuera Venezolanos Fuera" y después, el grupo de WhatsApp creado con el mismo nombre, creaban un sentido, un significado de rechazar al Otro, al venezolano inmigrante.

Facebook es un espacio digital per- fecto para realizar política y promoción, en el podemos generar debate, gracias a la facilidad de acceder a información, podemos conocer datos, propuestas, ideas. Los jóvenes que son usuarios asiduos de la tecnología y están en Facebook consumen gran cantidad de información de todo tipo. Generalmente Facebook es una fuente de información privilegiada para temas políticos y sociales.

Facebook al ser una red social, contacta a personas y permite una comunicación instantánea de todos los usuarios, podemos conocer a través de ella propuestas, ideas, pensamientos y solicitudes del público, estas propuestas pueden ser de manera individual o colectiva, llegando a ser masivas en poco tiempo. Esta plataforma puede convertir a un usuario que discute sobre temas y opciones en un actor político muy poderoso.

"Entonces ya subiendo, ya cuando hicimos todas esas cosas (quemaron cosas de ciudadanos venezolanos), por la calle Leoro Franco les decían que hagan reunión al compañero indígena que le comento (que había creado la página de Facebook "Fuera Venezolanos Fuera"); el joven se subió a uno de los basureros de los containers que hay en cada esquina; el joven dijo: paremos aquí, y dijo esto es una marcha pacífica y recuerden hermanos lo que hicimos todo eso estuvo bien. Claro porque estamos enojados..." (Entrevista a Jhony taxista Líder de la marcha, 2020).

\section{Acción Colectiva}

Movilización Colectiva y Masas 
Para poder caracterizar la marcha xenófoba del 20E en términos de Daniel Cefai (2011) se debe investigar sobre los contextos de experiencia de los actores. Los protagonistas que intervienen dentro de la movilización, son habitantes de Ibarra (transeúntes, usuarios de redes sociales, taxistas, etc.); en un plano Institucional, el Estado por medio de la Policía Nacional y la Policía Judicial, actores de la comunicación; como fue la Radio Canela. Los actores principales fueron los asistentes a la marcha; es necesario entender como entiende un ibarreño a su gente:

"Aquí en Ibarra ha sido así como una ciudad muy llevada por temas de la religión y cosas de esas también. Su nombre mismo lo dice la Ciudad Blanca, y es la Ciudad Blanca no por las paredes blancas, sino; porque se consideraban blancos. Para diferenciarse de los de los pueblos indígenas que tradicionalmente ha tenido esa idea de la pureza o de la pulcritud. No sé cómo llamarlo" (Entrevista a Andrés Játiva - Asistente a Marcha, 2020).

Se puede explicar el fenómeno de esta movilización colectiva a través de modelos de acción racional o de movilización de recursos, sin embargo, cuando equipamos a los agentes con sus capitales, económicos, culturales y sociales; estos están determinados por una posición y trayectoria del campo social "y son dotados de agenciamientos y de recursos que pueden ser específicos a un subcampo de la vida social" (Cefai, 2011, p.139). Se debe tomar en cuenta que el actor principal dentro de la marcha acor- de con las dos entrevistas realizadas, sentía furia e ira.

En términos de Maltoni y Poupeau (2007) el campo de los compromisos está restringido por un capital militante. Es hasta forzoso tratar de ampliar los intereses, para incluir intereses de preservación del orden normativo que guían la legitimidad de las acciones. Los actores tienden a rebelarse cuando las situaciones contradicen sus valores. Una de las limitantes de la teoría de la elección racional es que no abarca una economía general de las prácticas, que integre una economía de los bienes simbólicos. Cefai (2011) menciona que no existe un solo tipo de racionalidad, ni un solo tipo de legitimidad, sino "una multiplicidad de regímenes de compromiso y de justificación que se combinan unos con otros” (Cefai, 2011, p. 139).

El compromiso de los asistentes a la marcha estaba en función de un clamor; el clamor de no más violencia, aunque el resultado de su accionar generó el mismo resultado; sin embargo, querían paz en su ciudad.

"Lo más importante que quiero agregar en este tema de la muerte de Diana Carolina, la gente de Ibarra tuvo que hacer esto para que no haya mas violencia; porque aquí en Ibarra no queremos violencia; y la gente se une para que no haya violencia; eso lo sentí el día de la marcha siendo uno de los cabecillas de la marcha" (Entrevista a Jhony taxista Líder de la marcha, 2020).

Siguiendo la misma línea, Pizzor- 
no (1989) y Melucci (1996) rebaten la idea de que todo se puede colocar en términos de elección racional; para poder hacerlo, la situación debe colocarse en un marco de referencia que esté relacionado netamente con el cálculo. Las necesidades son carencias del ser; a las necesidades no se las puede manejar en términos relacionales; estas tienen objetivos simbólicos, afectivos e identitarios, mediante los cuales nos constituimos como uno solo y organizamos nuestra vida colectiva. La marcha del 20E no se la puede explicar desde un sentido de racionalidad, debido a que nadie recibió nada por asistir y tampoco por las acciones xenófobas, las emociones fueron claves en la marcha, saliéndose completamente de todo tipo de racionalidad

"En cuanto a las redes de organización se encuentran ligadas a las potencialidades de sus agenciamientos sociotécnicos. La capacidad para reaccionar no es solamente un asunto de las personas, es la punta extrema de una inteligencia colectiva y organizada" (Cefaï,2011, p. 149). Un celular en la actualidad significa potencialidades comunicativas de diferente nivel, desde un mensaje hasta una video llamada. Las redes sociales se han convertido en herramientas técnicas para "colectar, elaborar y sintetizar informaciones, identificar, acercar y convencer colectivos, debatir, tomar decisiones y difundirlas bajo un modo viral" (Cefai, 2011, p. 150).

(“...ocurre una movilización tan espontánea y tan grandes cantidades de personas. En los minutos desde que iniciaron los primeros mensajes virales en un máximo de dos horas, estaban concentradas en toda la ciudad unas 4000 a 5000 personas. Y todos con la consigna y consignas desde: "fuera venezolanos", "no los queremos...") (Entrevista a Andrés Játiva - Asistente a Marcha, 2020).

La marcha por sí sola generó compromisos individuales para que se pueda dar; la transversalización de la sensibilidad tuvo su catalizador en los videos y fotos de Diana Carolina; que en conjunto con la inseguridad, el desempleo y los aires de blanquitud de los ibarreños derivaron en una marcha xenófoba de ese nivel. Estas convocatorias estuvieron rondando por la ciudad de Ibarra por tres días consecutivos; sin embargo, solo el primer día se observó el desalojo de ciudadanos venezolanos de la ciudad. Aunque las movilizaciones fueron constantes y contundentes, no pasaron al siguiente nivel que es la adhesión de simpatizantes, tampoco un reclutamiento.

Para obtener una aproximación teórica empírica que dé cuenta del suceso el 20E es necesario realizarse la pregunta: ¿Qué es lo que quiere la gente? Dónde las metas y las tácticas reflejan la cultura y las emociones. Se debe indagar la motivación y los fines de la acción, investigar los puntos de vista de las personas; esto nos dará mejores respuestas.

La gente en la marcha buscaba un chivo expiatorio a todos los problemas sociales que les acosaban; es por esta razón que un enemigo silencioso 
construido en redes sociales y con el agravante de un asesinato, fue el detonante perfecto para echar culpas y buscar respuestas ante la inoperancia del mismo Estado.

En las sociedades modernas, acorde con Kornhauser (1969), tienen tendencias que son contrarias al orden democrático; es decir, tienen predisposición a desarrollar características de la sociedad de masas. El comportamiento de las masas no diferencia estrato social (Laraña, 1996, p. 20). Es por esta razón que se debe considerar a esta movilización desde una perspectiva de teoría de masas.

La marcha del 20E tiene un observable empírico que se asemeja bastante con el concepto de "comportamiento de masa"; cuya principal característica es el aspecto cognitivo de la acción; si bien la indignación sostenida por los habitantes de Ibarra en cuanto a los problemas sociales de inseguridad y desempleo que afectaban; el asesinato de Diana Carolina transmitido vía streaming desató el evento mediante la transversalidad de las redes sociales.

La capacidad que poseen los individuos en cuanto a sugestión e irritabilidad con características de este fenómeno, donde el malestar social configura el comportamiento colectivo (Park, 1939, p. 227). Además una de las principales características fue su tendencia y la incursión en el uso desmedido de la fuerza como medio para resolver un conflicto; por un momento Ibarra presenció un movimien- to fascista que recorría la ciudad, empleando la violencia hacia el enemigo construido imaginariamente (Laraña, 1996, p. 23).

Si bien la teoría de la sociedad de masas analiza los cambios estructurales en la configuración de la opinión pública y el surgimiento de públicos que carecen de otras fuentes de información que los mass media, con las cámaras de eco de Facebook estaremos ante este mismo escenario. Por tanto, esta teoría podría aplicarse al evento en cuanto a la opinión pública. Se debe recordar que una de las radios de Ibarra "Radio Canela 70.1", fue la única que transmitió el suceso en forma directa.

Acorde con Enrique Laraña (1996), las transformaciones estructurales se consideran las causas de los cambios que se producen en la cultura, los valores y sentimientos de la población, al igual que de sus formas de acción colectiva. Esta marcha xenófoba se sujeta en cambios de corte estructural, principalmente en los problemas de integración social producto de la migración; concluyendo en una disponibilidad casi inmediata de individuos dispuestos a movilizarse en pro de programas totalitarios, abrogar procedimientos democráticos mediante el uso de la violencia.

En un plano individual la persona dentro de la marcha desea formar parte de algo cuando participa en un movimiento de masas. Al estar dentro de una masa, la personalidad consciente del individuo es sustituida 
por la inconsciente y actúa como si estuviese hipnotizado. Es por esta razón que cuando se actúa en masa, se pueden realizar los crímenes más violentos y aberrantes a vista y oído de todos. Experimentan un sentimiento de potencia invencible que es otorgado gracias al anonimato que se extiende por todos los asistentes en un grupo numeroso. Después, una dinámica de sugestibilidad y contagio social hasta el punto de que el individuo sacrifica muy fácilmente su interés personal al colectivo. “...al formar parte de una masa, los individuos descienden varios peldaños en la escala de la civilización, sufren un bloqueo en sus estructuras cognitivas y se convierten en autómatas manejados por la inercia de la masa” (Laraña, 1996, p. 27).

\section{Acción Colectiva de las Emociones}

Abordando la acción colectiva de las emociones se debe definir qué es una emoción. Para Denzin es "una experiencia corporal viva, veraz, situada y transitoria que impregna el flujo de conciencia de una persona, que es percibida en el interior de y recorriendo el cuerpo, y que, durante el transcurso de su vivencia, sume a la persona y a sus acompañantes en una realidad nueva y transformada - la realidad de un mundo constituido por la experiencia emocional” (Denzin, 2009 [1984], p. 66). A diferencia de Kemper que ve a las emociones como "una compleja y organizada predisposición a participar en ciertas clases de conductas biológicamente adaptativas... caracterizada por unos peculiares estados de excitación fisiológica, unos peculiares sentimientos o estados afectivos, un peculiar estado de receptividad, y una peculiar pauta de reacciones expresivas” (Kemper, 1987, p. 267).

Brody ve las emociones "como sistemas motivacionales con componentes fisiológicos, conductuales, experienciales y cognitivos, que tienen una valencia positiva o negativa (sentirse bien o mal), que varían en intensidad, y que suelen estar provocadas por situaciones interpersonales o hechos que merecen nuestra atención porque afectan a nuestro bienestar" (Bericat, 2012, p. 2).

Para la presente investigación se tomará la definición de Brody, debido a que la movilización tuvo un componente fisiológico representado por el accionar de la marcha; conductual, por la conducta violenta de los asistentes, tras experiencias y cogniciones cargadas de la figura del Otro, en un marco asociativo por redes sociales.

"Entonces fuimos marchando y la gente empezó a decir por aquí vive tal, por acá está cual, aquí están más venezolanos, y me uní a jóvenes y empezamos a sacar a la gente; porque yo también estuve en eso. Sacamos colchones, sacábamos lavadoras. Todo quemamos, quemábamos hasta que fuimos a un hotel que quedaba en la Mosquera y Calixto Miranda que claro estaban ahí alojados jóvenes venezolanos. Entonces me acuerdo que un compañero amigo, subió a sacarles con toda la gente a la calle y me acuerdo que la gente ya enfurecida tenía toda la razón, cogieron una lavadora y la lanzaron del tercer piso y eso 
reventó y eso se hizo un problema; pero igual la gente seguía enfurecida, no estaba conforme y decía que si aquí tenemos que amanecernos, nos amanecemos, yo escuchaba; la gente que caminaba y también decía nos amanecemos" (Entrevista a Jhony taxista Líder de la marcha, 2020).

Acorde con Kemper y su teoría de la interrelacionalidad, la mayor parte de las emociones humanas se nutren y tiene sentido en el marco de las relaciones sociales; es decir, "la naturaleza de las emociones está condicionada por la naturaleza de la situación social en la que los hombres sienten" (Bericat, 2000, p. 150). Las emociones toman forma en el cuerpo y se traducen en sentimientos de: resentimiento, soledad, vergüenza, orgullo, tristeza, frustración, rabia, odio, y miedo, estos dos últimos, son sentimientos fuertes que pueden ser desencadenantes de una acción colectiva, al igual que la alegría.

Es necesario segregar un análisis emocional para dar cuenta de fenómenos como el nacionalismo o el patriotismo, en términos generales una identidad colectiva (Bericat , 2000, p. 150). Hay que tomar en cuenta que el fenómeno ocurrido en Ibarra tiene una relación con un nacionalismo construido a lo largo de la historia, es decir, en la formación misma de los estados, construyendo imaginarios del Otro en base a fronteras establecidas. "Yo soy ecuatoriano y él es venezolano".

En una de las citas de Le Bon, toma a Benoist indicando que existe un alma colectiva que piensa, se expresa, y sien- te como lo haría una persona o individuo. Hoy en día es importante advertir que las emociones son parte importante de una asociación, existen diferentes propuestas teóricas de la acción colectiva de emoción (Jasper, 1998; Goodwin, Jasper y Polletta, 2000; Jasper, 2012), estar en un movimiento colectivo representa un sinnúmero de emociones concatenadas unas con otras (Bleiker y Hutchison, 2008).

Las emociones están presentes en todas las fases y aspectos de la protesta (aquí los términos movimientos sociales y protesta se superponen lo suficiente como para usarlos de manera intercambiable); motivan a los individuos, se generan en la multitud, se expresan retóricamente y dan forma a los objetivos manifiestos y latentes de los movimientos. Las emociones pueden ser medios, también fines, y otras veces fusionan ambos; pueden favorecer o dificultar los esfuerzos de movilización, las estrategias y el éxito de los movimientos. La cooperación y la acción colectiva siempre han ofrecido la oportunidad de pensar la acción social de una forma más integral; el retorno de las emociones es la última fuente de inspiración para ello (Jasper, 2012, p. 49).

Jasper presenta una tipología basada en sentimientos acorde a su duración y forma en como se sienten:

"Las pulsiones [urges] son fuertes impulsos corporales difíciles de ignorar (...) Las emociones reflejas son reacciones a nuestro entorno físico y social inmediato (...) Los estados de ánimo perduran en el 
tiempo - de allí que podamos trasladarlos de un entorno a otro-, y se diferencian de las emociones porque carecen de un objeto directo" (Jasper, 2012, p. 48).

Tomaremos como material teórico a las emociones reflejas que en el caso de la marcha se tradujeron en expresiones corporales y faciales. Sin embargo Jasper realiza una nueva clasificación acorde a la estabilidad y al tiempo, el primero, las lealtades $\mathrm{u}$ orientaciones afectivas y el segundo las emociones; estas últimas nos interesan puesto que "se refieren a los sentimientos de aprobación o rechazo basados en intuiciones o principios morales; asimismo están relacionadas con la satisfacción de hacer lo correcto (o incorrecto), y también con la de sentir lo correcto (o incorrecto), como, por ejemplo, la compasión en torno a los desamparados o la indignación frente a una injusticia” (Jasper 2012, p. 48).

Otra explicación para el fenómeno del 20E es mostrado por la teoría de Scheff (e.g., 1990). Se ha mostrado el impacto del orgullo (y su opuesto, la vergüenza) en diferentes escenarios institucionales; "el orgullo genera y señala un vínculo seguro, al mismo tiempo que la vergüenza genera y señala un vínculo amenazado" (Scheff, 1994, p. 3). La vergüenza no reconocida, en particular, "conduce directamente a la ira, la ofensa y la agresión”, tal como lo demuestra el autor en su explicación de los orígenes de la primera y segunda guerras mundiales (Scheff, 1994, p. 5). Él observa la interpelación de Hitler a los alemanes de los años treinta a partir del rastreo de las manifestaciones de vergüenza de éste, y nos otorga una provechosa lista de claves verbales y visuales que nos permiten comprender esas emociones. Como consecuencia, cuando las partes de una interacción albergan vergüenza no reconocida, se hace más probable una escalada de violencia y una polarización. Como ejemplo, sería los movimientos gay, los cuales mostraban vergüenza y se asociaron para transformarla en orgullo. El 20E, puede ser que los individuos tengan vergüenza de ser xenófobos, sin embargo, al asociarse, esa xenofobia se transformó en orgullo y este en una escalada de violencia.

\section{Conclusiones}

Toda asociación de esta magnitud como la del 20E tiene un detonante, un suceso que conllevó a los demás, el femicidio de Diana Carolina, puede ser la respuesta debido a la cercanía de los eventos, además del shock emocional que representó éste para los asistentes. En esta marcha no se tienen organizadores visibles o identificables debido al anonimato que presentan las tecnologías de internet, las redes sociales, un enfoque de miedo y ansiedad con el Otro. El miedo y la ansiedad son producto de una insuficiencia o reducción en el poder de uno. 


\section{Bibliografía}

Bericat A, E. (2012). Emociones. Sociopedia. isa, 1-13.

Bericat, A, E. (2000). La sociología de la emoción y la emoción en la sociología. Papers: Revista de Sociología, 62, 145-176.

Bleiker, R., \& Hutchison, E. (2008). Fear no more: emotions and world politics. Review of International Studies, 34(S1), 115-135.

Candón-Mena, J. (2013). Toma la calle, toma las redes: el movimiento\# 15M en Internet. Atrapasueños.

Castells, M. (1999). El poder de la identidad. La era de la información. Madrid: Alianza Editorial.

Castells, M. (2001). Internet y la sociedad red. La Factoría, 14(15), 1-13.

Cefaï, (2011). "Diez propuestas para el estudio de las movilizaciones colectivas. De la experiencia al compromiso", Revista de Sociología, (26), 137-166.

Denzin NK (2009 [1984]). On Understanding Emotion. New Brunswick, NJ: Transaction Publishers.

El Comercio. (2019, 19 enero). Un hombre asesinó a una mujer tras tenerla retenida por 90 minutos en la calle en Ibarra. El Comercio. Recuperado de https://www.elcomercio.com

El Universo [Youtube]. (2019, 21 enero a). Turba enardecida desaloja a venezolanos en Ibarra [Archivo de vídeo]. Recuperado de https://www.eluniverso.com/2019/01/21/ video/7150712/turba-enardecida-desaloja-venezolanos-ibarra/

El Universo. (2019, 21 enero b). Manifestantes obligaron a desalojar a migrantes venezolanos en Ibarra tras caso de femicidio. Seguridad | Noticias | El Universo. Recuperado de https://www.eluniverso.com

El Universo. (2019, 21 enero c). En 11 ciudades de Ecuador se exigió frenar la violencia contra mujeres. Recuperado 6 de octubre de 2021, de https://www.eluniverso. com/noticias/2019/01/21/nota/7151099/marcha-contra-violencia-genero-pide-cambios-sistema-judicial/

Entrevista a Andrés Játiva - Asistente a Marcha [En persona]. (2020). Ibarra, de https://drive.google.com/file/d/1j8yZyWNTjQm6htr4tXSb7jYa4gu8OF3R/view?usp=sharing

Entrevista a Jhony taxista Líder de la marcha [En persona]. (2020). Ibarra, de https://drive. google.com/file/d/1UMddH3RRQxsqd0E5DpoHdUZ9wMTmxsCu/view?usp=sharing

Comentario de página Facebook "Aquí hablamos en serio". (2017, 8 septiembre). Comentarios de Facebook [Publicación de Facebook]. Recuperado de https://www.facebook.com/100050543196866/videos/1598611916825964

Goodwin, J., Jasper, J., \& Polletta, F. (2000). The return of the repressed: The fall and rise of emotions in social movement theory. Mobilization: An International Quarterly, $5(1), 65-83$.

Gordillo, E. (2021, 6 octubre). Re: Capturas de Pantalla y Transcripciones de las entrevistas [Link]. Recuperado de https://docs.google.com/document/d/1r69JfuTGj1ufMEGtvxnvdvZBBaQ_P5Vz/edit?usp=sharing\&ouid=114503308928131671882\&rtpof=true\&sd $=$ true

Guerrero, O. F. (2015). Levinas y la alteridad: cinco planos. Brocar. Cuadernos de Investigación Histórica, (39), 423-443.

Jasper, J. (1998). "The emotions of protest, affective and reactive emotions in and around social movements, Sociological”, Journal Forum, (3), 397-424. 
Jasper, J. (2012). "Las emociones y los movimientos sociales: veinte años de teoría e investigación*”. Revista Latinoamericana de Estudios sobre Cuerpos, Emociones y Sociedad, 48-68.

Kemper TD (1987). How many emotions are there? Wedding the social and autonomic components. American Journal of Sociology, 93, 263-289.

Kornhauser, W. (1969). Aspectos políticos de la sociedad de masas (No. 301.4 KORa).

La República. (2017, 15 septiembre). Venezolana tilda de «indios y feos» a ecuatorianos y desata debate migratorio. Recuperado 5 de octubre de 2021, de https://www.larepublica.ec/blog/2017/09/15/venezolana-tilda-de-indios-y-feos-a-ecuatorianos-y-desata-debate-migratorio/

Laraña, E. (1996). "La actualidad de los clásicos y las teorías del comportamiento colectivo”, Reis, No. 74, 15-43.

Melucci, A. (1996). Challenging codes: Collective action in the information age. Cambridge University Press.

Park, R. E. (1939). Symbiosis and socialization: A frame of reference for the study of society. American Journal of Sociology, 45(1), 1-25.

Pizzorno, A. (1989). Algún otro tipo de alteridad: una crítica a las teorías de la elección racional. Sistema: Revista de Ciencias Sociales, (88), 27-42.

Poupeau, F., \& Matonti, F. (2007). El capital militante. Intento de definición. Dominación y movilizaciones. Estudios sociológicos sobre el capital militante y el capital escolar. Córdoba: Ferreira Editor, 37-44.

Samoná, L., (2005). Diferencia y alteridad. Después del estructuralismo: Derrida y Levinas. Madrid, Akal.

Scheff, T. J. (1990). Microsociology: Discourse, emotion, and social structure. University of Chicago Press.

Scheff, T. J. (1994). Bloody revenge. Boulder: Westview.

Telégrafo, E. (2019, 24 febrero). Asamblea apunta a error de mando en femicidio de Diana. El Telégrafo. Recuperado de https://www.eltelegrafo.com.ec

Toret, J. (2013). “Tecnopolítica: la potencia de las multitudes conectadas. El sistema red 15M como nuevo paradigma de la política distribuida”, Grupo DatAnalysis 15m, Accesible en: http://datanalysis15m.wordpress.com/2013/06/20/lanzamiento-tecnopolitica-y-15m- la-potencia-de-las-multitudes-conectadas-el-sistema-red-15m-un-nuevo-paradigma-de-la- politica-distribuida

Youtube. (2017, 14 septiembre). Venezolana llama a los Ecuatorianos indios feos y asquerosos [Archivo de vídeo]. Recuperado de https://www.youtube.com/watch?v=vMlDiMUaa44 